\title{
Generalized Additive Models Analysis of the Atmospheric Pollutants Response to the Emission Reduction and Meteorology During the COVID-19 Lockdown in the North of Africa (Morocco)
}

salah eddine sbai ( $\square$ salaheddinechimie@gmail.com)

Universite Mohammed V de Rabat Faculte des Sciences https://orcid.org/0000-0001-9607-7253

farida Bentayeb

UM5A: Universite Mohammed V de Rabat

Hao Yin

Chinese Academy of Sciences

\section{Research Article}

Keywords: COVID-19, GAMs model, Atmosphere, Pollution, Photochemical oxidation, Meteorological factors

Posted Date: November 23rd, 2021

DOI: https://doi.org/10.21203/rs.3.rs-1029027/v1

License: @ (i) This work is licensed under a Creative Commons Attribution 4.0 International License. Read Full License 


\section{Abstract}

Climate and air quality change due to COVID 19 lockdown (LCD) are extremely concerned subjects of several research recently. The contribution of meteorological factors and emission reduction to air pollution change over the north of Morocco has been investigated in this study using the framework generalized additive models (GAM), that have been proved to be a robust technique for the environmental data sets, focusing on main atmospheric pollutants in the region including ozone $\left(\mathrm{O}_{3}\right)$, nitrogen dioxide $\left(\mathrm{NO}_{2}\right)$, sulfur dioxide $\left(\mathrm{SO}_{2}\right)$, particulate matter $\left(\mathrm{PM}_{2.5}\right.$ and $\left.\mathrm{PM} 10\right)$, secondary inorganic aerosols (SIA), nom-methane volatile organic compounds (NMVOC) and carbon monoxide (CO) from the regional air pollution dataset of the Copernicus Atmosphere Monitoring Service (CAMS). Our results indicate that secondary air pollutants $\left(\mathrm{PM}_{2.5}, \mathrm{PM}_{10}\right.$ and $\left.\mathrm{O}_{3}\right)$ are more influenced by metrological factors and the other air pollutants reported by this study in comparison with primary air pollutants $\left(\mathrm{NO}_{2}\right.$ and $\mathrm{SO}_{2}$. We found that meteorological factors contribute to $\mathrm{O}_{3}, \mathrm{PM}_{2.5}, \mathrm{PM}_{10}$ and SIA average mass concentration by $22 \%, 5 \%, 3 \%$ and $34 \%$ before LCD and by $28 \%, 19 \%, 5 \%$ and $42 \%$ during LCD respectively. The increase in meteorological factors effect during LCD shows the contribution of photochemical oxidation to air pollution due to increase in atmospheric oxidant $\left(\mathrm{O}_{3}\right.$ and $\mathrm{OH}$ radical) during $\mathrm{LCD}$, which can explain the response of $\mathrm{PM}$ to emission reduction. Our study indicates that $\mathrm{PM}\left(\mathrm{PM}_{2.5}, \mathrm{PM}_{10}\right)$ has more controlled by $\mathrm{SO}_{2}$ due to the formation of sulfate particles especially under high oxidants level. The positive correlation between westward wind at 10m (WW10M), Northward Wind at 10m (NW10M) and PM indicates the implication of sea salt particles transported from Mediterranean Sea and Atlantic Ocean. This study shows the contribution of atmospheric oxidation capacity to air pollution change.

\section{Introduction}

Aware of the state of degradation of its natural resources, Morocco has adopted an environmental policy based essentially on the concept of sustainable development. He intends to make environmental protection a factor in the country's economic and social development. The national debate on regional planning and the organization in Morocco of the $22^{\text {nd }}$ conference of the countries parties to the convention on climate change (COP 22 ) in 2016 show the effective commitment of Morocco, like several countries in development, to make the environment one of the components of sustainable development.

The COVID-19 pandemic has severely affected daily life, including the economic, social and health sectors. The restriction of human activities during the spread of COVID-19 had a major impact on air quality and climate change due to the decrease in the atmospheric pollutants levels like nitrogen dioxide, sulfur dioxide and carbon monoxide, etc (Otmani et al., 2020; Berman and Ebisu, 2020; Zambrano-Monserrate et al., 2020; Bao and Zhang, 2020; Bassani et al., 2021). However, several studies have shown a sharp increase in ozone which could increase the atmospheric oxidative capacity (Sharma et al., 2020; Tobías et al., 2020). In the atmosphere, ozone could transform into $\mathrm{OH}$ radicals in the presence of humidity, according to the two reactions $\mathrm{O}_{3}+$ hv $\rightarrow \mathrm{O}_{2}+\mathrm{O}_{(1 \mathrm{D})}$ and $\mathrm{O}(1 \mathrm{D})+\mathrm{H}_{2} \mathrm{O} \rightarrow 2 \mathrm{OH}$ (Peng et al., 2015). Ozone could also be reacted with other pollutants that are not related to human activities like biogenic volatile organic compounds (BVOC) or volatile organic compounds ( $\mathrm{VOC}$ ) and sulfur dioxide $\left(\mathrm{SO}_{2}\right)$, leading to the formation of secondary organic aerosols ( $\mathrm{SOA}$ ) or secondary inorganic aerosols (SIA) which represents a significant fraction of PM (Abis et al., 2021; Srivastava et al., 2018). This could explain the increase in PM or the small decrease found in comparison with other pollutants, according to results of several studies (Sbai et al., 2021b ;Chauhan and Singh, 2020; Dantas et al., 2020).

The metrological conditions can play a vital role during atmospheric oxidation, since the formation of oxidants $\left(\mathrm{O}_{3}\right.$ and $\mathrm{OH}$ radical) is strongly controlled by meteorological parameters like humidity (Tillmann et al., 2010), UV radiation (Bais et al., 2018), temperature (Wu et al., 2011), and planetary boundary layer height (Su et al., 2018). COVID19 LCD gives an important opportunity to the study and analysis the transformation of many atmospheric pollutants and also the contribution of meteorological parameters in atmospheric pollution. Understanding the response of air pollution to emissions reduction due to COVID-19 LCD will provide important clues regarding health and emissions control and forecasting trends in air pollution.

Advances in the numerical methods recently of linear models enhanced the capability to understanding the atmospheric environmental processes (Ravindra et al., 2019). A mathematical basis for the assessment of atmospheric parameters, and providing comparative significance of different variables can be easily understood using statistical methods (Ravindra et al., 2016). Generalized additive models (GAM) is recently adopted as analytical methods in atmospheric environment by several researchers (Ravindra et al., 2019; Yin et al., 2021; Zhang et al., 2019). GAMs model can be used to assess the consequence of air pollutants and climate change on human health, to evaluate the impact of metrological factors on atmospheric pollution level or primary and secondary air pollution relationship under different conditions. Furthermore, GAM model also was utilized to understand the driving forces of air pollution evolution and evaluate the efficiency of emission controls ( Zhang et al., 2019).

We investigate individual effect of metrological factors and their contribution to air pollutants formation. Moreover, we evaluate the contribution of each pollutant to the formation of the other air pollutants and change in anthropogenic emissions effect on the variation of air quality over Morocco using GAM model. To this effect, the concentrations of main atmospheric pollutants in the region including ozone $\left(\mathrm{O}_{3}\right)$, nitrogen dioxide $\left(\mathrm{NO}_{2}\right)$, sulfur dioxide $\left(\mathrm{SO}_{2}\right)$, particulate matter $\left(\mathrm{PM}_{2.5}\right.$ and $\mathrm{PM}_{10}$ ), secondary inorganic aerosols (SIA), nom-methane volatile organic compounds (NMVOC) and carbon monoxide (CO) from the regional air pollution dataset of the Copernicus Atmosphere Monitoring Service (CAMS) were used in the GAM model that has been adopted as the best approach to study the environment and climate change. This study provides useful insights into the contribution of photochemistry involving $\mathrm{O}_{3}$ and $\mathrm{OH}$ oxidation as an alternative pathway to air pollution during emission reduction.

\section{Methods}

The change in air pollution level due to COVID19 LCD has been widely studied by several studies in Europe, Asia especially in China and India and also in South America such as US, Brazil, Mexico, and Argentina, etc. However, in Africa the study of climate change due to COVID19 LCD is very limited due to lack of data or access to dataset. In the Morocco atmospheric pollution data is not subject to distribution to the public. In addition, there are only 29 measuring

Page 2/16 
stations distributed throughout the country do not provide sufficient temporal resolution of air quality, which requires the search for an optimal alternative source to carry out studies based on high resolution data. $\mathrm{PM}_{10}, \mathrm{PM}_{2.5}, \mathrm{NO}_{2}, \mathrm{SO}_{2}, \mathrm{NMVOC}, \mathrm{SIA}$ and $\mathrm{O}_{3}$ mass concentrations of Copernicus Atmosphere Monitoring Service Reanalysis (CAMSRA) data have been used. This study is the first in North Africa according to our knowledge which will focus on the global change in main atmospheric air pollution.

\section{Study area}

Located at the northwestern end of the African continent, Morocco has a privileged geostrategic position with a maritime frontage extending over approximately $3,500 \mathrm{~km}$, opening onto the Mediterranean to the north, with a coast of approximately $500 \mathrm{~km}$, and on the Atlantic Ocean to the West with a coastline of about $3000 \mathrm{~km}$. The Mediterranean coast is rich in natural sites and landscapes with some points of high population density, in particular between Tangier and Casablanca. The Atlantic coast concentrates the largest agglomerations reaching the highest densities. It is served by a relatively dense road and communication network. It also has the largest hydrographic network since the largest rivers flow into the Atlantic Ocean. Morocco is bounded on the east by Algeria and on the south by Mauritania. The surface of Morocco reaches $710850 \mathrm{~km}^{2}$, of which a large part is covered with mountainous zones. The Rif, the Middle and the High Atlas, the main mountain ranges in Morocco, reach heights that vary between 2000 to over $4000 \mathrm{~m}$. The highest point, Toubkal, located in the High Atlas, reaches $4165 \mathrm{~m}$ (figure S1).

The Moroccan climate is both Mediterranean and Atlantic, with a dry and hot season doubled by a cold and wet season, the end of the hot period being marked by the October rains. The presence of the sea attenuates temperature variations, moderates the seasons and increases the humidity of the air (400 to $1000 \mathrm{~mm}$ of rainfall on the coast). In the interior, the climate varies according to the altitude. Summer wind blowing from the Sahara. In this season, the average temperatures are $22^{\circ} \mathrm{C}$ to $24^{\circ} \mathrm{C}$. Winters are cold and rainy with frost and snow. The average temperature then changes from $-2^{\circ} \mathrm{C}$ to $14^{\circ} \mathrm{C}$ and can drop to $-26^{\circ} \mathrm{C}$. In mountainous regions, precipitation is very high (more than $2,000 \mathrm{~mm}$ of precipitation in the Rif or even $1,800 \mathrm{~mm}$ in the Middle Atlas). PreSaharan and Saharan Morocco has a dry desert climate.

\section{Atmospheric pollutants mass concentration data}

The Copernicus Atmosphere Monitoring Service (CAMS) database produces daily air quality analyses and forecasts for the European and north Africa with higher horizontal resolution $\left(0.1^{\circ} \times 0.1^{\circ}(10 \mathrm{~km} \times 10 \mathrm{~km})\right.$ than is available from the global analyses and forecasts and horizontal coverage extends from $25.0^{\circ} \mathrm{W}$ to $45.0^{\circ} \mathrm{E}$ and $30.0^{\circ} \mathrm{S}$ to $70.0^{\circ} \mathrm{N}$. The production is based on an ensemble of nine air quality forecasting systems across Europe. A median ensemble is calculated from individual outputs, since ensemble products yield on average performance than the individual model products. The spread between the nine models are used to estimate the forecast uncertainty. The data cover all study area were investigated, in terms of mass concentration of the different air pollutants before LCD (between $3^{\text {rd }}$ and $28^{\text {th }}$ February 2020) and During LCD (between $3^{\text {rd }}$ and $28^{\text {th }}$ April 2020). The daily average mass concentrations for main atmospheric pollutants including ozone $\left(\mathrm{O}_{3}\right)$, nitrogen dioxide $\left(\mathrm{NO}_{2}\right)$, sulfur dioxide $\left(\mathrm{SO}_{2}\right)$, particulate matter $\left(\mathrm{PM} \mathrm{M}_{2.5}\right.$ and $\mathrm{PM}$ 10), Secondary inorganic aerosols (SIA) and nom-methane volatile organic component (NMVOC) from the regional air pollution data of the Copernicus Atmosphere Monitoring Service CAMS (CAMS 2021).

\section{Meteorological conditions data}

The meteorological conditions significantly influence air pollutants formation and their evolution in atmosphere (Chen et al., 2020). Meteorological data used in this study including surface air temperature (SAT), relative humidity (RH), Eastward wind at 10m (EW10M), Northward Wind at 10m (NW10M), Total Precipitation (TP), Irradiance, Planetary Boundary Layer Height (PBLH) for the period extending from $3^{\text {rd }}$ to $28^{\text {th }}$ February (Before LCD) and $3^{\text {rd }}$ to $28^{\text {th }}$ April (during LCD) over north of Morocco, were downloaded from Giovanni earth data (Giovanni, 2021).

\section{Data analysis}

All data were downloaded as NetCDF files from CAMS and Giovanni. Data visualization and preprocessing were performed by Panoply data viewer version 4.12.7.0. The ArcGis 10.8 was used for map representation using three-Dimensional (3D) (latitude, longitude, and time) NetCDF file. For modelization, 3D data has been transformed into $2 \mathrm{D}$ and GAM model was conducted using the gam modeling function in the R package version 4.1 .0 (open source statistical software and language) with the 'mgcv' library.

\section{GAMs Model}

To assess the contribution of meteorological factors report above. We applied a statistical adjustment method based on the GAMs model. Moreover, the contribution of each pollutant to formation of others air pollutants was evaluated by GAM model. To explain the impact of individual factors on air pollutants, we used the effect of the smooth term $\mathrm{S}(\mathrm{Xi})$ in $\mathrm{GAM}$ model, where $\mathrm{Xi}$ is the individual factor and $\mathrm{S}(\mathrm{Xi})$ represents the relative effect of meteorological factor on each pollutant mass concentration (Ravindra et al., 2019; Grüss et al., 2014 ; Yin et al., 2021 ; Zhang et al., 2019).

The GAMs model uses penalized smoothing splines to estimate the marginal effect of individual meteorological factors and pollutant concentrations on the air quality trends. Unlike previous studies based on the atmospheric chemistry model, this new statistical method based on long-term satellite observations provides an explicit solution to assess natural and anthropogenic impacts and estimate the role of emission control measures on air quality levels (Zhang et al., 2019). The nonparametric shape of the model it is very flexible, allowing it to reveal the nonlinear effect of independent parameters. The smoothness of each function is controlled by the number of knots or effective number of degrees of freedom (Yin et al., 2021). Here, the smoothing parameters were estimated by restricted maximum likelihood (REML) (Wood, 2004).

\section{Results And Discussion}


To assess air pollution change during and before the LCD period, several studies have compared the pollutants level during the LCD period and the average of the pollutants level during the 3,5 or 7 previous years to suppress meteorological conditions effect. CAMS dataset does not provide sufficient data for a few previous years and the pollution level changes from one year to another, for this reason we have compared the level of each pollutant for one month before LCD and one month during LCD and we subtracted the meteorological effect using the GAM model.

\section{Spatial patterns for main air pollutions $\left(\mathrm{O}_{3}, \mathrm{NO}_{2}, \mathrm{SO}_{2}, \mathrm{PM}_{2.5}\right.$, and $\left.\mathrm{PM}_{10}\right)$ before and during COVID-19 pandemic lockdown over north of Morocco}

The south and east of Morocco are characterized by high-temperature levels which explain the high concentrations of ozone found in this area compared to the north and west (figure 1a). In addition, the car density in the south and east is lower than that of the north, which means that ozone titration by nitrogen oxide in the north is much important than in the south-eastern. We also observed that $\mathrm{O}_{3}$ mass concentration increased sharply during LCD over all the study area and does not exceed the OMS limit value $120 \mathrm{ug} / \mathrm{m}^{3}$. The same results were found by several researches (Zhao et al., 2021), this behavior that can be due to the reduction of ozone titration by nitrogen monoxide (NO) carbon monoxide (CO) and sulfur dioxide ( $\left.\mathrm{SO}_{2}\right)$ during $\mathrm{LCD}$ period.

Figure $1 \mathrm{~b}$ shows spatial distribution for $\mathrm{NO}_{2}$ mass concentrations before and during $\mathrm{LCD}$, we clearly observed that the highest concentrations of $\mathrm{NO}_{2}$ are found in the north and the center (Casablanca, Rabat, and Marrakech), however we show that the level of $\mathrm{NO}_{2}$ does not exceed limit value $\left(40 \mu \mathrm{g} / \mathrm{m}^{3}\right.$ ). During the LCD, $\mathrm{NO}_{2}$ dropped dramatically in all the zone which is in agreement with all that is found by other studies in Europe (chauhan and Singh et al.,2021), Asia (Shen et al., 2021) or America (Cazorla et al., 2021), the decrease in $\mathrm{NO}_{2}$ during LCD is due to the reduction in road traffic which represents the main source of $\mathrm{NO}_{2}$. Moreover, we show also that the $\mathrm{O}_{3}$ and $\mathrm{NO}_{2}$ spatial distributions are inversely correlated which prove that the increase in $\mathrm{O}_{3}$ during $\mathrm{LCD}$ is due to the reduction in its titration by $\mathrm{NO}_{2}$.

The main sources of sulfur dioxide $\left(\mathrm{SO}_{2}\right)$ in Morocco are constituted by the burning of fossil fuels (e.g., oil and coal) and the smelting of mineral ores that contain sulfur. $\mathrm{SO}_{2}$ is one of the important indicators of air pollutants that are strongly related to the combustion of coal, petroleum, and chemical fuel emissions. It is the major precursor of nucleation formation of new particles in the atmosphere; and when these processes occur in populated regions, they could increase the human exposure to ultrafine particles, the highest $\mathrm{SO}_{2}$ mass concentrations are observed in the region of Casablanca, Rabat and tangier, the major industrial cities in the country. Generally, the level of sulfur dioxide in the study area is very low (figure S2).

This figure $1 \mathrm{c}$ and Figure $\mathrm{S} 2$ show the spatial distribution of $\mathrm{PM}_{2.5}$ (particulate matter with aerodynamic diameter less than 2.5um) and PM 10 (particulate matter with aerodynamic diameter less than 10um), we observe that $\mathrm{PM}_{2.5}$ and $\mathrm{PM}_{10}$ have similar distribution and $\mathrm{PM}_{2.5}$ and $\mathrm{PM}_{10}$ increase in the $\mathrm{North}_{\text {and }}$ East of the study area during LCD. This finding can be explained by two arguments: the increase in the ozone level over the Mediterranean Sea and Atlantic Ocean in the north and northwest (Figure S3), promotes the formation of sea salt particles like iodine by $\mathrm{O}_{3}$ oxidation or $\mathrm{OH}$ radical oxidation (Sbai and farida 2019b; Tham et al., 2021). In addition, sea salt particle can be transported by the north-south or west-east direction wind and contribute to increase in PM. Besides, the industrial activities especially phosphate production has not been completely suspended. Some study also indicate an increase in PM accumulation mode by $20 \%$, this was explained by improvement of nucleation and growth process during the LCD period, due to the higher formation rate of $2 \mathrm{~nm}$ particles and the subsequent growth rate (Shen et al., 2021).

\section{Daily variation for $\mathrm{O}_{3}, \mathrm{NO}_{2}, \mathrm{CO}, \mathrm{SO}_{2}, \mathrm{PM}_{2.5}, \mathrm{PM}_{10}$ and SIA before and during COVID-19 pandemic lockdown in the Casablanca}

Figure 3 shows daily variation for $\mathrm{O}_{3}, \mathrm{NO}_{2}, \mathrm{CO}, \mathrm{SO}_{2}, \mathrm{PM}_{2.5}, \mathrm{PM}_{10}$ and SIA before and during of COVID-19 pandemic LCD in the Casablanca industrial capital of Morocco. Daily variation of ozone mass concentration during and before LCD display the same trends, $\mathrm{O}_{3}$ slowly increases after the sun rises from the morning at 8:00 a.m. and reaches its maximum at 1:00p.m. at noon, afterward it remains stable at 120ug/ $\mathrm{m}^{3}$ during the LCD (figure $2 \mathrm{a}$ ), this behavior can be explained by the reduction in gases titrating nitrogen monoxide and carbon monoxide after 10:00a.m (figure $2 \mathrm{~b} \& 2 \mathrm{c}$ ). In addition, the increase in temperature and solar radiation during the day promotes the production of ozone. The highest concentrations of $\mathrm{NO}_{2}$ and $\mathrm{CO}$ were found during the morning between 8:00 and 10:00 (figure $2 \mathrm{~b} \& 2 \mathrm{c}$ ), during the peak road traffic period that represents their main source, $\mathrm{NO}_{2}$ before and during LCD have same trends indicating no change in the emission source. Daily variation of $\mathrm{PM}_{2.5}, \mathrm{PM}_{10}$ and $\mathrm{SIA}$ indicate no special change during the morning or in the middle of the day their concentrations remain stable throughout the day except a slight increase for $\mathrm{PM}_{2.5}$ similar diurnal variations in $\mathrm{PM}_{10}$ and $\mathrm{PM}_{2.5}$ concentrations were found.

\section{Marginal effect of individual meteorological variables s(meteos) on $\mathrm{PM}_{2.5}$ and $\mathrm{PM}_{10}$ mass concentration}

Figure 3 and figure S4 show marginal effect of individual meteorological variables s(meteos) on $\mathrm{PM}_{2.5}$ and $\mathrm{PM}_{10}$ mass concentration. A negative effect for $\mathrm{PBHL}$, total precipitation and NW10M on PM $\left(\mathrm{PM}_{2.5}\right.$ and $\left.\mathrm{PM}_{10}\right)$, this meteorological parameters contribute to decrease in $\mathrm{PM}_{2.5}$ by $9 \%, 2 \%$ and $9 \%$ respectively, before LCD and $8 \%, 1 \%$ and $5 \%$ respectively during LCD (Table 1). However, a positive marginal effect was found for SAT, Irradiance and RH that contribute to increase $\mathrm{PM}_{2.5}$ by $9 \%, 12 \%$ and $18 \%$ respectively, before LCD and $17 \%, 54 \%$ and $34 \%$ respectively during LCD. The relationship between (SAT \& Irradiance) and (PM) exhibits the role of photochemistry in the formation of PM especially during emission reduction, this result can be due to the rise in temperature that can leads to increase in precursor gases emission like VOC and BVOC and oxidants $\left(\mathrm{O}_{3}\right.$ and $\mathrm{OH}$ radical) that can promotes the formation of PM by secondary pathway (Friedman et al., 2016; Sbai et al., 2021a). Negative value of NW10M represents SW10M and shows inverse correlation with PM. However, the NW10M display positive effect, this can be explained by the transport of sea salt particles from ocean in the north. In addition, several studies have reported that sea salts particles especially iodine particle contribute to $\mathrm{PM}_{2.5}$ (Shi et al., 2021). West Wind at 10 meter (WW10M) the negative values of EW10M, show a positive effect which indicate the contribution of sea salt particles transported from the Mediterranean Sea. However, EW10M (positive values) its effect remains almost null which shows that there is no contribution of the dust mineral particles from Sahara. 
Planetary boundary layer height (PBLH) is an important parameter in the dilution of near-surface pollutants and vertical mixing. However, the relationship between PBLH and surface pollutants, especially $\left(\mathrm{PM}_{2.5}\right.$ and $\left.\mathrm{PM}_{10}\right)$ concentration is not yet well understood (Su et al., 2018). We show a negative effect for PBHL on PM mass concentration, because their emission or secondary formation mainly occurs at the surface. A recent study reported a negative correlations PBHL and PM for most cases, and their relationship depends on location, meteorological conditions, and season (Su et al., 2018). Also, an independent PBLH-PM relationship is observed over the clean area, whereas negative correlations are found over the polluted areas. Relatively strong dependence are observed when the PBLH is low and PM level is high (Su et al., 2018). The absorbing aerosol has a potential factor influencing the PBLH-PM relationships, much higher absorbing aerosol loading is reported to have strong interaction with the PBLH via a positive correlation (Ding et al., 2016; Dong et al., 2017).

The positive correlation between PM mass concentrations and the RH due to the heterogeneous reactions and the formation of SOA via photochemical reaction that can enhanced under high $\mathrm{RH}$ level, because reaction of water molecule with $\mathrm{O}(1 \mathrm{D})$ oxygen atoms is the main pathway for $\mathrm{OH}$ radicals formation (Wang et al., 2016 ; Q. Zhang et al., 2019; Sbai and Farida, 2019). Thereby, causing an increase in PM mass concentration. Several studies have observed that PM increase with RH and this was partially explained by the aqueous-phase reactions, gas-particle partitioning and water uptake (Jia and Xu, 2014; Qu et al., 2015).

\section{Marginal effect of individual pollutants $\left(\mathrm{O}_{3}, \mathrm{NO}_{2}, \mathrm{SO}_{2}, \mathrm{NMVOCs}\right)$ mass concentration on $\mathrm{PM}\left(\mathrm{PM}_{10}\right.$ and $\left.\mathrm{PM}_{2.5}\right)$ level}

$\mathrm{PM}_{2.5}$ and $\mathrm{PM}_{10}$ display same response to individual pollutants marginal effect, $\mathrm{PM}$ and $\mathrm{O}_{3}$ show a negative correlation during LCD that growth with $\mathrm{O}_{3}$ level. $\mathrm{O}_{3}$ contributes to a slight decrease (6\%) in $\mathrm{PM}_{2.5}$ (Figure 4). High ozone level promote fragmentation reactions that can generates species with high volatility and low molecular weight that does not effectively condense to form particles and consequently PM mass decrease, this can also be explained by the positive correlation found before LCD period when the atmosphere is loaded with precursor gases that can be oxidized by ozone and formed secondary aerosols. Some researchers reported that $\mathrm{PM}$ and $\mathrm{O}_{3}$ show a nonlinear relationship since $\mathrm{O}_{3}$ increases with PM at low to moderate and declines at higher PM (Buysse et al., 2019). The PM gas precursors emissions especially VOCs and $\mathrm{SO}_{2}$ has been reduced due to the suspension of industrial activities and the increase of oxidants $\left(\mathrm{O}_{3}\right.$ and $\left.\mathrm{OH}\right)$ during $\mathrm{LCD}$ can contribute to heterogeneous reactions at the particle surface which lead to decline PM mass (Ding, 2003). That could explain the negative correlation between ozone and PM. Besides, sulfur dioxide has a positive correlation with PM and contributes significantly to PM mass concentration by $29 \%$ and $22 \%$ during LCD and by $44 \%$ and $41 \%$ before LCD for $\mathrm{PM}_{2.5}$ and $\mathrm{PM}_{10}$ respectively (Table1). Evidently, the high contribution before LCD due to high $\mathrm{SO}_{2}$ level, this finding is most likely due to the formation of sulfate particles from $\mathrm{SO}_{2}$ oxidation, which contributes to the increase in the mass of PM. Jiang et al show that the sulfate is the dominant component in PM in the atmosphere of Guangzhou in china (Jiang et al., 2019).

During LCD the emission of anthropogenic VOC was reduced due to restriction of industrial activities. However, the BVOC emission enhanced with temperature. In addition, the formation of fine particles by oxidation of $\mathrm{BVOC}$ like isoprene and a-pinene decreased with increase in $\mathrm{NO}_{2}$ levels due to the formation of high volatility products ( $\mathrm{Ng}$ et al., 2007), which explains the reversal $\mathrm{NO}_{2}$ dependence of PM during LCD (figure 4). On the other hand, the positive $\mathrm{NO}_{2}-\mathrm{PM}$ correlation obtained before $\mathrm{LCD}$ is explained by the presence of anthropogenic VOCs which can be oxidized by ozone, nitrate radical ( $\mathrm{NO}_{3}$ ) or $\mathrm{OH}$ radicals and produces secondary organic aerosols (SOA) which represent a large fraction of PM (Mancilla et al., 2015; Waring and Wells, 2015). The negative correlation of the $\mathrm{NO}_{2}$-PM during LCD versus positive correlation before LCD could be the result of a number of factors: under high- $\mathrm{NO}_{2}$ levels (before $L C D$ ), $\mathrm{RO}_{2}$ reacts predominantly with nitrogen monoxide, while under low- $\mathrm{NO}_{2}$ levels (during $\mathrm{LCD}$ ) peroxy radicals react mainly with $\mathrm{HO}$. The higher $\mathrm{PM}$ formation under high $\mathrm{NO}_{2}$ conditions due to alkoxy radicals (RO) formation that isomerizes rather than fragments (Baldwin et al., 1977). The isomerization leads to the formation of large hydro-xycarbonyls $\left(\mathrm{CHO}_{2}\right)$, multifunctional products with low volatility that can be condensed in the particle phase and consequently contribute to increasing PM mass concentration. Furthermore, the isomerization depends on the size of RO radicals (Atkinson et al., 2006). Moreover, higher $\mathrm{PM}$ level observed under high- $\mathrm{NO}_{2}$ conditions due to non-volatile organic nitrate formation ( $\mathrm{Ng}$ et al., 2007). Also, we observed a positive trend between NMVOC and PM, especially at a mass concentration $\left(>7 \mu \mathrm{g} / \mathrm{m}^{3}\right)$ and contributes to a slight increase in PM. The NMVOC can be considered as precursor gases their oxidation by ozone or $\mathrm{OH}$ radical leads to the formation of low volatility species which can condense and form particles, however their effect remains very moderate due to their low concentration in the region.

\section{Marginal effect of individual meteorological variables $\mathrm{s}$ (meteos) on $\mathrm{O}_{3}$ mass concentration}

The Ozone mass concentration shows convincing tendency of increase with RH, PBLH, Irradiance, Total precipitation, and SAT (figure 5). Temperature and Irradiance enhance photochemical ozone formation during the LCD period and caused an increase in $\mathrm{O}_{3}$ by $50 \%$ and $10 \%$ respectively compared to other meteorological parameters (Table 1). Higher levels of solar irradiation could promote the rise of $\mathrm{O}_{3}$ at the surface because intense solar radiation can lead to the enhancement of photochemical reactions producing ozone (Jasaitis et al., 2016). In addition, the increase in temperature enhance VOC and BVOC emission that can lead to $\mathrm{O}_{3}$ formation (Bai, 2021). Ozone mass concentrations in the upper boundary layer are higher than in the lower boundary layer (He et al., 2021), higher boundary layer (PBHL) is conducive to the transport of ozone from the upper layer, which can explain the positive correlation obtained for PBLH greater than $1000 \mathrm{~m}$ that caused an increase to $\mathrm{O}_{3}$. Humidity contributes to increase ozone by $20 \%$ at RH ( $\left.<60 \%\right)$ during LCD. However, we show a negative correlation between $\mathrm{RH}$ and $\mathrm{O}_{3}$ at $\mathrm{RH}(>60 \%)$ because high $\mathrm{RH}$ contribute to the destruction of ozone by a catalytic reaction cycle resulting in enhanced ozone destruction causes the formation of hydroxyl $(\mathrm{OH})$ and hydroperoxy $\left(\mathrm{HO}_{2}\right)$ radicals. Moreover, NW10M and EW10M seem to have relatively little effect on the $\mathrm{O}_{3}$ level. EW10M contribute to a low decrease in $\mathrm{O}_{3}$ because high ozone levels are found in the west over sea, SW10M has a negative effect that decrease with reduction in wind speed (figure 5).

\section{Marginal effect of individual pollutants $\left(\mathrm{PM}_{10}, \mathrm{PM}_{2.5}, \mathrm{NO}_{2}, \mathrm{SO}_{2}, \mathrm{NMVOC}\right)$ mass concentration on ozone level}


Figure 6 shows a negative correlation between ozone and PM $\left(\mathrm{PM}_{2.5}\right.$ and $\left.\mathrm{PM}_{10}\right)$ contributing to drop in ozone by about $10 \%$ during LCD and $38 \%$ respectively before LCD (Table 1). This can be explained by the photochemical aging of particles via ozone and $\mathrm{OH}$ radical oxidation, leading to changes in the chemical and physical properties of particles (Kang et al., 2018). Some studies discovered that SOA formed by $\mathrm{O}_{3}$ and OH oxidation of VOCs absorb UV irradiation at atmospherically wavelengths (Romonosky et al., 2016), leading to rich photochemistry within the particles (aging) such as direct photodissociation of carbonyl (Mang et al., 2008) and peroxide (Epstein et al., 2013). Photochemical reaction into the oxidized particle contributes to their aging these reactions lead to a loss in the mass of the particles (Walser et al., 2007). We show also a negative marginal effect of $\mathrm{SO}_{2}$ on ozone which amplifies with the increase of $\mathrm{SO}_{2}$ mass concentration and causing a decrease in $\mathrm{O}_{3}$ by $49 \%$ during LCD and $15 \%$ before LCD (figure 6 ), this behavior can be due to heterogeneous oxidation of $\mathrm{SO}_{2}$ by $\mathrm{O}_{3}$ and sulfate particle formation.

The $\mathrm{NO}_{\mathrm{x}}$ has a dual impact on ozone concentration, since that can contribute to the production and depletion of ozone, during LCD period nitrogen oxide $\left(\mathrm{NO}_{2}\right.$ and NO) mass concentration decrease and consequently ozone depletion via $\mathrm{NO}$ reaction, which can explain the positive correlation between ozone and $\mathrm{NO}_{2}$ during LCD period that contributed to increase $\mathrm{O}_{3}$ by $12 \%$. Before LCD we find a negative effect of $\mathrm{NO}_{2}$ because under high $\mathrm{NOx}$ level $\mathrm{O}_{3}$ depletion via $\mathrm{NO}$ reaction more important than $\mathrm{O}_{3}$ production via $\mathrm{NO}_{2}$ reaction because the rate constant of $\mathrm{NO}$ reaction with ozone is almost 1000 times higher than that of $\mathrm{NO}_{2}$ reaction with ozone, that can explain the negative correlation before LCD. In our previous study we have shown that ozone depletion has decreased by $50 \%$ during LCD (Sbai et al., 2021b).

Non-methane volatile organic compounds (NMVOCs) were widely emitted from a variety of sources, including the transportation sector, solvent use, industry and biomass burning (Li et al., 2017). The NMVOCs are important ozone gas precursors and affect strongly the tropospheric ozone chemistry and play key roles in $\mathrm{O}_{3}$ formation (Li et al., 2019), which is in perfect agreement with the positive correlation obtained in this study (Figure 6). Previous studies revealed that ethylene, toluene, xylene and propylene are estimated to be the key NMVOC precursors in ozone formation (Li et al., 2017).

\section{Marginal effect of individual meteorological variables $\mathrm{s}$ (meteos) on primary air pollutants $\left(\mathrm{SO}_{2}\right.$ and $\left.\mathrm{NO}_{2}\right)$ mass concentration}

Figure S6 and S7 represent the effect of individual meteorological variables s(meteos) on primary air pollutants $\left(\mathrm{SO}_{2}\right.$ and $\left.\mathrm{NO}_{2}\right) \mathrm{mass}$ concentration. We show a negative dependence of $\mathrm{NO}_{2}$ to $\mathrm{RH}$, total precipitation and irradiance, causing a decrease in $\mathrm{NO}_{2}$ by $11 \%, 9 \%$ and $11 \%$ respectively during $\mathrm{LCD}$ and $21 \%$, $1 \%$ and $48 \%$ respectively before $\mathrm{LCD}$ (Table 1 ). In addition, reversal dependence was observed between $\mathrm{SO}_{2}$ and $\mathrm{RH}$, total precipitation and irradiance, contributing to decline in $\mathrm{SO}_{2}$ by $24 \%, 1 \%$ and $36 \%$ respectively during LCD and $24 \%, 1 \%$ and $61 \%$ respectively before LCD (Table1). The high level of water vapor in the atmosphere promotes $\mathrm{NO}_{2}$ conversion to nitric acid $\left(\mathrm{HNO}_{3}\right)$ and $\mathrm{SO}_{2}$ to sulfuric acid $\left(\mathrm{H}_{2} \mathrm{SO}_{4}\right)$, which explains the negative effect of $\mathrm{RH}$. Furthermore, high humidity and irradiation enhanced $\mathrm{OH}$ radical formation by the photolysis of ozone in the presence of water vapor, consequently $\mathrm{OH}$ radical react with $\mathrm{SO}_{2}$ and form sulfur trioxide $\left(\mathrm{SO}_{3}\right)$ that can associated with water molecule to produce $\mathrm{H}_{2} \mathrm{SO}_{4}$. The negative marginal effect of $\mathrm{PBHL}$ indicates that $\mathrm{NO}_{2}$ and $\mathrm{SO}_{2}$ are mainly controlled by primary emission from the surface. The $\mathrm{SAT}$ shows a positive correlation with both $\mathrm{NO}_{2}$ and $\mathrm{SO}_{2}$ and we have observed the same trend before the end during LKD. Some studies found that temperatures above $40^{\circ} \mathrm{C}$ contributed to the increase of $\mathrm{NO}_{2}$ by $120 \%$, this finding is explained by the influence of temperature on evaporative emission rates or the association between meteorological parameters essential to $\mathrm{NO}_{2}$ and surface temperatures (Pearce et al., 2011). Previous studies report also a positive relationship between $\left(\mathrm{NO}_{2}\right.$ and $\left.\mathrm{SO}_{2}\right)$ and temperature during heat waves (Theoharatos et al., 2010) and non-heat wave periods using GAMs models (Pearce et al., 2011). We have observed a linear positive effect of WW10M on $\mathrm{SO}_{2}$ however SW10M display a small effect; this can be explained by the location of industrials sites in North and West. EW10M has a positive effect on $\mathrm{NO}_{2}$ level but SW10M displays a negative effect, both decreases with wind speed because in north and east car density is high and contributed to high $\mathrm{NO}_{2}$ level production in this area.

\section{Marginal effect of individual meteorological variables s(meteos) vs marginal effect of individual pollutants $s$ (pollutants)}

Figure 7 shows the marginal effect of the pollutants $\mathrm{s}$ (pollutants) and the metrological factors $\mathrm{s}$ (meteos). The $\mathrm{s}$ (meteos) and $\mathrm{s}$ (pollutants) values indicate that the secondary pollutants $\left(\mathrm{PM}_{2.5}, \mathrm{PM}_{10}\right.$ and $\left.\mathrm{O}_{3}\right)$ are more influenced by the other pollutants and the metrological parameters reported by this study in comparison to $\mathrm{NO}_{2}$ and $\mathrm{SO}_{2}$. The s(meteos) and s(pollutants) contribute to $\mathrm{O}_{3}$ average mass concentration by $28.6 \mu \mathrm{g} / \mathrm{m}^{3}$ and $71.4 \mathrm{ug} / \mathrm{m}^{3} \mathrm{during} \mathrm{LCD}$ and by $9.1 \mu \mathrm{g} / \mathrm{m}^{3}$ and $67.1 \mu \mathrm{g} / \mathrm{m}^{3}$ before LCD respectively. While s(meteos) contributes to $\mathrm{PM}_{2.5}$ and $\mathrm{PM}_{10}$ by $1.5 \mu \mathrm{g} / \mathrm{m}^{3} 0.6 \mu \mathrm{g} / \mathrm{m}^{3}$ before $\mathrm{LCD}$ and $0.7 \mu \mathrm{g} / \mathrm{m}^{3}$ and $0.6 \mu \mathrm{g} / \mathrm{m}^{3}$ respectively during LCD. Moreover, s(pollutants) contributes to $\mathrm{PM}_{2.5}$ and $\mathrm{PM}_{10}$ by $6.6 \mu \mathrm{g} / \mathrm{m}^{3}$ and $12.1 \mu \mathrm{g} / \mathrm{m}^{3}$ before $\mathrm{LCD}$ and by $12.3 \mu \mathrm{g} / \mathrm{m}^{3}$ and $20.4 \mu \mathrm{g} / \mathrm{m}^{3}$ during LCD respectively (figure 8 ). This finding shows that meteorological factors could not explain the increase in PM and ozone during LCD, so that the main reasons for this increase were photochemical phenomena involving $\mathrm{O}_{3}$ and $\mathrm{OH}$ radical oxidation and chemical process effects. That show also that atmospheric potential oxidation is enhanced during LCD due to rise in ozone and some radicals like $\mathrm{OH}_{\text {and }} \mathrm{HO}_{2}$ that can be produced from $\mathrm{O}_{3}$ photochemistry. In addition, we show that s(meteos) increase during LCD for all pollutants due to decline in some pollutants concentration. The difference

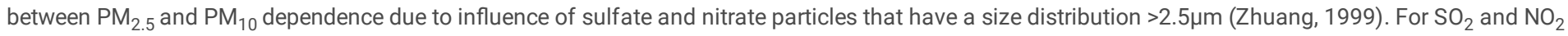
are controlled rather by primary emissions that can explained their slight dependence. Ozone and SIA were not influenced in the same way as other secondary pollutants $\left(\mathrm{PM}_{2.5}\right.$ and $\left.\mathrm{PM}_{10}\right)$ by metrological factors $\mathrm{s}$ (meteos) and other pollutants $\mathrm{s}$ (pollutants) because they depend on other atmospheric pollutants that are not reported by this study such as VOC, BVOC, and ammonia.

Table 1: Summary of marginal effect of individual meteorological variables s(meteos) and individual pollutants S(pollutants) 


\begin{tabular}{|c|c|c|c|c|c|c|c|c|c|c|c|c|}
\hline \multirow{3}{*}{ polluants } & \multirow{3}{*}{$\begin{array}{l}\text { Avrage Mass } \\
\text { Concentration } \\
\mu \mathrm{g} / \mathrm{m}^{3}\end{array}$} & \multicolumn{11}{|c|}{ During Covid19 lockdown } \\
\hline & & \multicolumn{10}{|c|}{$\mathrm{S}(\mathrm{meteos}) \%$} & $\leqslant$ \\
\hline & & $\mathrm{S}(\mathrm{RH})$ & \multicolumn{2}{|c|}{ S(irradiance) } & $\mathrm{S}(\mathrm{TP})$ & \multicolumn{2}{|r|}{$\mathrm{S}(\mathrm{PBHL})$} & $S(T)$ & \multicolumn{2}{|r|}{$\mathrm{S}(\mathrm{NW10M})$} & $\mathrm{S}(\mathrm{EW} 10 \mathrm{M})$ & ( \\
\hline $\mathrm{O}_{3}$ & 102.1 & 20 & \multicolumn{2}{|l|}{10} & 0 & \multicolumn{2}{|r|}{10} & 50 & \multicolumn{2}{|r|}{5} & 5 & - \\
\hline $\mathrm{PM}_{2.5}$ & 13.0 & 34 & \multicolumn{2}{|l|}{12} & 17 & \multicolumn{2}{|r|}{8} & 17 & \multicolumn{2}{|r|}{4} & 8 & $\epsilon$ \\
\hline $\mathrm{PM}_{10}$ & 21.1 & 5 & \multicolumn{2}{|l|}{27} & 7 & \multicolumn{2}{|r|}{4} & 18 & \multicolumn{2}{|r|}{17} & 22 & ; \\
\hline $\mathrm{SO}_{2}$ & 4.1 & 24 & \multicolumn{2}{|l|}{36} & 1 & \multicolumn{2}{|r|}{6} & 30 & \multicolumn{2}{|r|}{0} & 3 & 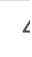 \\
\hline $\mathrm{NO}_{2}$ & 3.8 & 11 & \multicolumn{2}{|l|}{11} & 10 & \multicolumn{2}{|r|}{23} & 11 & \multicolumn{2}{|r|}{0.0} & 34 & ; \\
\hline \multirow[t]{3}{*}{ SIA } & 4.6 & 20 & \multicolumn{2}{|l|}{40} & 0.0 & \multicolumn{2}{|r|}{10} & 30 & \multicolumn{2}{|r|}{0.0} & 0.0 & 2 \\
\hline & & Before & Covid & 9 lockdown & & & & & & & & \\
\hline & & $\mathrm{S}$ (mete & s) $\%$ & & & & & & & & & \\
\hline polluants & $\begin{array}{l}\text { Avrage Mass } \\
\text { Concentration } \\
\mu \mathrm{g} / \mathrm{m}\end{array}$ & & & & & & & & & & & \\
\hline & & & RH) & S(irradiance) & & $S(T P)$ & $\mathrm{S}(\mathrm{PBHL})$ & & $S(T)$ & $S(N W)$ & $S(E W)$ & \\
\hline $\mathrm{O}_{3}$ & 76.2 & 17 & & 35 & & 13 & 9 & & 17 & 0 & 9 & \\
\hline $\mathrm{PM}_{2.5}$ & 8.1 & $1 \varepsilon$ & & 54 & & 2 & 9 & & 9 & 9 & 0 & \\
\hline $\mathrm{PM}_{10}$ & 12.7 & 2 & & 43 & & 7 & 10 & & 0 & 12 & 0 & \\
\hline $\mathrm{SO}_{2}$ & 9.8 & 2 & & 61 & & 1 & 6 & & 1 & 6 & 1 & \\
\hline $\mathrm{NO}_{2}$ & 9.4 & 2 & & 48 & & 1 & 7 & & 17 & 0 & 6 & \\
\hline SIA & 4.9 & 25 & & 51 & & 1 & 6 & & 13 & 0 & 4 & \\
\hline
\end{tabular}

\section{Conclusion}

Air pollution change in Africa linked to the 2019 Novel Coronavirus (COVID-19) LCD has not attracted too much attention unlike other continents. In this work, we have studied the change in air pollution due to COVID-19 LCD over north of Morocco in Africa. Using GAM model that has been adopted as an analysis method recently by several studies in the atmospheric environment. During COVID-19 LCD emission of primary air pollution decline due to restriction of human activities which gave us an opportunity to assess the atmospheric oxidation capacity and its contribution to air pollution. We observed the increase in secondary pollutants $\left(\mathrm{PM}_{10}, \mathrm{PM}_{2.5}, \mathrm{SIA}\right.$ and $\left.\mathrm{O}_{3}\right)$ despite the emissions reduction contrary to several studies, greatly developed our curiosity to discover the factors driving this trend. We have adopted GAM model as an analysis method to assess the contribution of meteorological parameters $s$ (meteos) as well as the contribution of each pollutant $s$ (pollutants) to atmospheric pollution. The results show an positive effect for $s\left(m^{2}\right.$ eteos) on Ozone, $\mathrm{PM}$ ( $\left.\mathrm{PM} \mathrm{M}_{10}, \mathrm{PM}_{2.5}\right)$ and $\mathrm{SIA}$. This finding can be explained by enhancement in photochemical reaction involving $\mathrm{O}_{3} / \mathrm{OH}$ oxidation of $\mathrm{VOC}, \mathrm{BVOC}$ and $\mathrm{SO}_{2}$ leading to $\mathrm{SOA}_{\text {and }} \mathrm{SIA}$ particles formation, rise in s(meteos) effect on PM and SIA under high oxidants level (during LCD) can confirm this conclusion. We show also a strong increase in $\mathrm{O}_{3}$ and PM over Mediterranean Sea (west) and Atlantic Ocean (north) during LCD, which can be due to sea salt oxidation that enhanced under high level in atmospheric oxidants $\left(\mathrm{O}_{3}\right.$ and $\mathrm{OH}$ radical). Moreover, sea salt particles transported by the wind towards the urban environment and contribute to PM increase over Morocco, this hypothesis can be supported by the positive correlation between (WW10M, NW10M) and PM. This study shows that LCD can not be sufficient sometimes to improve air quality for this reason another policy measure must be adopted.

\section{Declarations}

Ethics approval This article does not contain any studies with human participants or animals performed by any of the authors.

Consent to participate Not applicable.

Consent for publication Not applicable.

Authors Contributions Salah Eddine Sbai: Conceptualization, Methodology, Software, Validation, Formal analysis, Investigation, Writing-original draft, Visualization. Farida Bentayeb supervision. Hao Yin Software, and Validation.

Funding Not applicable.

Competing interests The authors declare no competing interests. 
Availability of data and materials Data are available by contacting the corresponding author, the data for the pollutant concentration is Available at Copernicus Atmosphere Monitoring Service European air quality forecasts website: https://ads.atmosphere.copernicus.eu/cdsapp\#!/search and metrological data can be found at Giovanni earth website: https://giovanni.gsfc.nasa.gov/giovanni//.

\section{References}

Abis L, Kalalian C, Lunardelli B, Wang T, Zhang L, Chen J, Perrier S, Loubet B, Ciuraru R, George C (2021). Measurement report: Biogenic volatile organic compound emission profiles of rapeseed leaf litter and its secondary organic aerosol formation potential. Atmospheric Chem Phys 21:12613-12629. https://doi.org/10.5194/acp-21-12613-2021

Atkinson R, Baulch DL, Cox RA, Crowley JN, Hampson RF, Hynes RG, Jenkin ME, Rossi MJ, Troe J (2006) Evaluated kinetic and photochemical data for atmospheric chemistry: Volume II - gas phase reactions of organic species. Atmospheric Chem Phys 6:3625-4055. https://doi.org/10.5194/acp-6-3625-2006

Bai, J., (2021) 03 Concentration and Its Relation with BVOC Emissions in a Subtropical Plantation Atmosphere 12:711. https://doi.org/10.3390/atmos12060711

Bais AF, Lucas RM, Bornman JF, Williamson CE, Sulzberger B, Austin AT, Wilson SR, Andrady AL, Bernhard G, McKenzie RL Aucamp PJ, MadronichS, Neale RE, Yazar S, Young, AR (2018). Environmental effects of ozone depletion, UV radiation and interactions with climate change: UNEP Environmental Effects Assessment Panel, update (2017) Photochem Photobiol Sci 17: 127-179. https://doi.org/10.1039/C7PP90043K

Baldwin AC, Barker JR, Golden DM, Hendry DG, (1977). Photochemical smog. Rate parameter estimates and computer simulations. J Phys Chem 81, 24832492. https://doi.org/10.1021/j100540a027

Bao R, Zhang A, (2020) Does lockdown reduce air pollution? Evidence from 44 cities in northern China. Sci Total Environ. 731, 139052. https://doi.org/10.1016/j.scitotenv.2020.139052

Bassani C, Vichi F, Esposito G, Montagnoli M, Giusto M, lann- iello A (2021) Nitrogen dioxide reductions from satellite and surface observations during COVID19 mitigation in Rome (Italy). Environ Sci Pollut Res 1-24. https:// doi. org/ 10. 1007/

s11356- 020- 12141-9

Berman JD, Ebisu K (2020) Changes in U.S. air pollution during the COVID-19 pandemic. Sci Total Environ 739, 139864.

https://doi.org/10.1016/j.scitotenv.2020.139864

Buysse CE, Kaulfus A, Nair U, Jaffe DA (2019). Relationships between Particulate Matter, Ozone, and Nitrogen Oxides during Urban Smoke Events in the Western US. Environ Sci Technol 53, 12519-12528. https://doi.org/10.1021/acs.est.9b05241

(CAMS 2021) Copernicus Atmosphere Monitoring Service European air quality forecasts. 2021. Available

at https://ads.atmosphere.copernicus.eu/cdsapp\#!/search. latest accessed at 28 August 2021.

Cazorla M, Herrera E, Palomeque E, Saud N (2021) What the COVID-19 lockdown revealed about photochemistry and ozone production in Quito, Ecuador. Atmospheric Pollut Res 12, 124-133. https://doi.org/10.1016/j.apr.2020.08.028

Chauhan A, Singh RP (2020) Decline in PM2.5 concentrations over major cities around the world associated with COVID-19. Environ Res 187, 109634. https://doi.org/10.1016/j.envres.2020.109634

Chen Z, Chen D, Zhao C, Kwan M, Cai J, Zhuang Y, Zhao B, Wang X, Chen B, Yang J, Li R, He B, Gao B, Wang K, Xu B (2020) Influence of meteorological conditions on PM2.5 concentrations across China: A review of methodology and mechanism. Environ Int 139: 105558.

https://doi.org/10.1016/j.envint.2020.105558

Dantas G, Siciliano B, França BB, da Silva CM, Arbilla G (2020) The impact of COVID-19 partial lockdown on the air quality of the city of Rio de Janeiro, Brazil. Sci Total Environ 729:139085. https://doi.org/10.1016/j.scitotenv.2020.139085

DingAJ Huang X, Nie W, Sun JN, Kerminen VM, Petäjä T, Su H, ChengYF, Yang, XQ (2016) Enhanced haze pollution by black carbon in megacities in China. Geophys Res Lett 43: 2873-2879. https://doi.org/10.1002/2016GL067745

Ding J (2003) Heterogeneous reactions on the surface of fine particles in the atmosphere. Chin Sci Bull 48:2267. https://doi.org/10.1360/03wb0046

Dong Z, Li Z, Yu X Cribb M, Li X, Dai J (2017) Opposite long-term trends in aerosols between low and high altitudes: a testimony to the aerosol-PBL feedback. Atmospheric Chem Phys 17: 7997-8009. https://doi.org/10.5194/acp-17-7997-2017

Epstein SA, Tapavicza E, Furche F, Nizkorodov SA (2013) Direct photolysis of carbonyl compounds dissolved in cloud and fog droplets. Atmospheric Chem Phys 13:9461-9477. https://doi.org/10.5194/acp-13-9461-2013

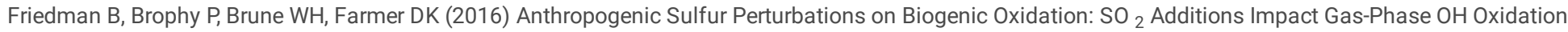
Products of $a-$ and $\beta$-Pinene. Environ Sci Technol 50:1269-1279. https://doi.org/10.1021/acs.est.5b05010 
Grüss A, Drexler M, Ainsworth CH (2014) Using delta generalized additive models to produce distribution maps for spatially explicit ecosystem models. Fish Res 159:11-24. https://doi.org/10.1016/j.fishres.2014.05.005

He G, Deng T, Wu D, Wu C, Huang X, Li Z, YinC, Zou Y, Song L, Ouyang S, Tao L, Zhang X (2021 Characteristics of boundary layer ozone and its effect on surface ozone concentration in Shenzhen, China: A case study. Sci Total Environ. 791:148044. https://doi.org/10.1016/j.scitotenv.2021.148044

Jasaitis D, Vasiliauskienè V, Chadyšienè R, Pečiulienè M (2016) Surface Ozone Concentration and Its Relationship with UV Radiation, Meteorological Parameters and Radon on the Eastern Coast of the Baltic Sea. Atmosphere 7, 27. https://doi.org/10.3390/atmos7020027

Jia L, Xu Y (2014) Effects of Relative Humidity on Ozone and Secondary Organic Aerosol Formation from the Photooxidation of Benzene and Ethylbenzene. Aerosol Sci Technol. 48:1-12. https://doi.org/10.1080/02786826.2013.847269

Jiang F, Liu F, Lin Q, Fu Y (2019) Characteristics and Formation Mechanisms of Sulfate and Nitrate in Size-segregated Atmospheric Particles from Urban Guangzhou, China. Aerosol Air Qual. Res. 19: 1284-1293. https://doi.org/10.4209/aaqr.2018.07.0251

(Giovanni 2021) Giovanni earth data the bridge between data and science. 2021. Available at https://giovanni.gsfc.nasa.gov/giovanni//. Latest accessed at 30 August 2021.

Kang E, Lee M, Brune WH, Lee T, Park T, Ahn J, Shang X (2018) Photochemical aging of aerosol particles in different air masses arriving at Baengnyeong Island, Korea. Atmospheric Chem Phys 18: 6661-6677. https://doi.org/10.5194/acp-18-6661-2018

Li M, Liu H, Geng G, Hong C et al (2017) Anthropogenic emission inventories in China: a review. Natl. Sci. Rev. 4, 834-866.

https://doi.org/10.1093/nsr/nwx150

Li M, Zhang Q, Zheng B, Tong D et al (2019) Persistent growth of anthropogenic non-methane volatile organic compound (NMVOC) emissions in China during 1990-2017: drivers, speciation and ozone formation potential. Atmospheric Chem. Phys. 19, 8897-8913. https://doi.org/10.5194/acp-19-8897-2019

Mancilla Y, Herckes P, Fraser MP, Mendoza A (2015) Secondary organic aerosol contributions to PM2.5 in Monterrey, Mexico: Temporal and seasonal variation. Atmospheric Res. 153: 348-359. https://doi.org/10.1016/j.atmosres.2014.09.009

Mang SA, Henricksen DK, Bateman AP et al (2008) Contribution of Carbonyl Photochemistry to Aging of Atmospheric Secondary Organic Aerosol. J Phys Chem A 112:8337-8344. https://doi.org/10.1021/jp804376c

$\mathrm{Ng} \mathrm{NL}$, Chhabra PS, Chan AWH et al (2007) Effect of NOx level on secondary organic aerosol (SOA) formation from the photooxidation of terpenes. Atmos Chem Phys 7:5159-5174. https://doi.org/10.5194/acp-7-5159-2007

Otmani A, Benchrif A, Tahri M, Bounakhla M (2020) Impact of Covid-19 lockdown on PM10, SO2 and NO2 concentrations in Salé City (Morocco). Sci Total Environ. 735, 139541. https://doi.org/10.1016/j.scitotenv.2020.139541

Pearce JL, Beringer J, Nicholls N, Hyndman RJ, Tapper NJ (2011) Quantifying the influence of local meteorology on air quality using generalized additive models. Atmos Environ 45: 1328-1336. https://doi.org/10.1016/j.atmosenv.2010.11.051

Peng Z, Day DA, Stark H, Li R (2015) HOx radical chemistry in oxidation flow reactors with low-pressure mercury lamps systematically examined by modeling. Atmospheric Meas Tech 8:4863-4890. https://doi.org/10.5194/amt-8-4863-2015

Qu WJ, Wang J, Zhang XY, Wang D, Sheng LF (2015) Influence of relative humidity on aerosol composition: Impacts on light extinction and visibility impairment at two sites in coastal area of China. Atmo Res 153: 500-511. https://doi.org/10.1016/j.atmosres.2014.10.009

Ravindra K, Rattan P, Mor S, Aggarwal AN (2019) Generalized additive models: Building evidence of air pollution, climate change and human health. Environ Int 132: 104987. https://doi.org/10.1016/j.envint.2019.104987

Ravindra K, Sidhu MK, Mor S, John S, Pyne S (2016) Air Pollution in India: Bridging the Gap between Science and Policy. J Hazard Toxic Radioact Waste 20. https://doi.org/10.1061/(ASCE)HZ.2153-5515.0000303

Romonosky DE, Ali NN, Saiduddin MN, et al (2016) Effective absorption cross sections and photolysis rates of anthropogenic and biogenic secondary organic aerosols. Atmos Environ 130:172-179. https://doi.org/10.1016/j.atmosenv.2015.10.019

Sbai SE, Farida B (2019) Photochemical aging and secondary organic aerosols generated from limonene in an oxidation flow reactor. Environ Sci Pollu Res 26: 18411-18420. https://doi.org/10.1007/s11356-019-05012-5

Sbai SE, Li C, Boreave A, Charbonnel N et al (2021) Atmospheric photochemistry and secondary aerosol formation of urban air in Lyon, France. J Environ Sci 99:311-323. https://doi.org/10.1016/j.jes.2020.06.037

Sbai SE, Mejjad N, Norelyaqine A, Bentayeb F (2021b) Air quality change during the COVID-19 pandemic lockdown over the Auvergne-Rhône-Alpes region, France. Air Qual Atmo Health 14: 617-628. https://doi.org/10.1007/s11869-020-00965-w 
Sbai SE, Farida B (2019) Study of lodine Oxide Particles at the Air/Sea Interface in the Presence of Surfactants and Humic Acid. Chem Chem Technol 13:341346. https://doi.org/10.23939/chcht13.03.341

Sharma M, Jain S, Lamba BY (2020) Epigrammatic study on the effect of lockdown amid Covid-19 pandemic on air quality of most polluted cities of Rajasthan (India). Air Qual. Atmo Health 13, 1157-1165. https://doi.org/10.1007/s11869-020-00879-7

Shen X, Sun J, Yu F, Wang Y et al (2021) Enhancement of nanoparticle formation and growth during the COVID-19 lockdown period in urban Beijing. Atmo Chem Phys 21:7039-7052. https://doi.org/10.5194/acp-21-7039-2021

Shi X, Qiu X, Chen Q, Chen S (2021) Organic lodine Compounds in Fine Particulate Matter from a Continental Urban Region: Insights into Secondary Formation in the Atmosphere. Env Sci Technol 55: 1508-1514 https://doi.org/10.1021/acs.est.0c06703

Srivastava D, Favez O, Perraudin E, Villenave E, Albinet A (2018) Comparison of Measurement-Based Methodologies to Apportion Secondary Organic Carbon (SOC) in PM2.5: A Review of Recent Studies. Atmosphere 9, 452. https://doi.org/10.3390/atmos9110452

Su T, Li Z, Kahn R (2018) Relationships between the planetary boundary layer height and surface pollutants derived from lidar observations over China: regional pattern and influencing factors. Atmo Chem Phys 18:15921-15935. https://doi.org/10.5194/acp-18-15921-2018

Tham YJ, He XC, Li Q, Cuevas C et al (2021) Direct field evidence of autocatalytic iodine release from atmospheric aerosol. Proc Natl Acad Sci 118, e2009951118. https://doi.org/10.1073/pnas.2009951118

Theoharatos G, Pantavou K, Mavrakis A, Spanou A et al (2010) Heat waves observed in 2007 in Athens, Greece: Synoptic conditions, bioclimatological assessment, air quality levels and health effects. Environ Res 110: 152-161. https://doi.org/10.1016/j.envres.2009.12.002

Tillmann R, Hallquist M, Jonsson ÅM, Kiendler-Scharr, et al (2010) Influence of relative humidity and temperature on the production of pinonaldehyde and OH radicals from the ozonolysis of a-pinene. Atmospheric Chem Phys 10: 7057-7072. https://doi.org/10.5194/acp-10-7057-2010

Tobías A, Carnerero C, Reche C, Massagué J, et al (2020) Changes in air quality during the lockdown in Barcelona (Spain) one month into the SARS-CoV-2 epidemic. Sci Total Environ. 726: 138540. https://doi.org/10.1016/j.scitotenv.2020.138540

Walser ML, Park J, Gomez AL, Russell AR, Nizkorodov SA (2007) Photochemical aging of secondary organic aerosol particles generated from the oxidation of d-limonene. J Phys Chem A. 15,1907-13. doi: 10.1021/jp066293I.

Wang G Zhang R Gome ME Yang L et al (2016) Persistent sulfate formation from London Fog to Chinese haze. Proc Natl Acad Sci 113: 13630-13635. https://doi.org/10.1073/pnas.1616540113

Waring MS, Wells JR (2015) Volatile organic compound conversion by ozone, hydroxyl radicals, and nitrate radicals in residential indoor air: Magnitudes and impacts of oxidant sources. Atmos Environ 106: 382-391. https://doi.org/10.1016/j.atmosenv.2014.06.062

Wood SN (2004) Stable and Efficient Multiple Smoothing Parameter Estimation for Generalized Additive Models. J Am Stat Assoc 99:673-686. https://doi.org/10.1198/016214504000000980

Wu LY, Tong SR, Wang WG, Ge MF (2011) Effects of temperature on the heterogeneous oxidation of sulfur dioxide by ozone on calcium carbonate. Atmospheric Chem Phys. 11: 6593-6605. https://doi.org/10.5194/acp-11-6593-2011

Yin H, Liu C, Hu Q et al (2021)Opposite impact of emission reduction during the COVID-19 lockdown period on the surface concentrations of PM2.5 and O3 in Wuhan, China. Environ. Pollut. 289, 117899. https://doi.org/10.1016/j.envpol.2021.117899

Zambrano-Monserrate MA, Ruano MA, Sanchez-Alcalde L (2020) Indirect effects of COVID-19 on the environment. Sci Total Environ 728:138813. https://doi.org/10.1016/j.scitotenv.2020.138813

Zhang C, Liu C, HuQ, Cai Z, et al (2019) Satellite UV-Vis spectroscopy: implications for air quality trends and their driving forces in China during $2005-2017$. Light Sci Appl 8, 100. https://doi.org/10.1038/s41377-019-0210-6

Zhang Q, Zheng Y, Ton D et al (2019) Drivers of improved PM 2.5 air quality in China from 2013 to 2017. Proc Natl Acad Sci. 116: 24463-24469. https://doi.org/10.1073/pnas.1907956116

Zhao Z, Zhou Z, Russo A, Xi H, Zhang J, DuH, Zhou C (2021) Comparative analysis of the impact of weather conditions and human activities on air quality in the Dongting and Poyang Lake Region during the COVID-19 pandemic. Atmos Pollut Res 12, 101054. https://doi.org/10.1016/j.apr.2021.101054

Zhuang H (1999) Size distributions of particulate sulfate, nitrate, and ammonium at a coastal site in Hong Kong. Atmos Environ 33: 843-853. https://doi.org/10.1016/S1352-2310(98)00305-7

\section{Figures}



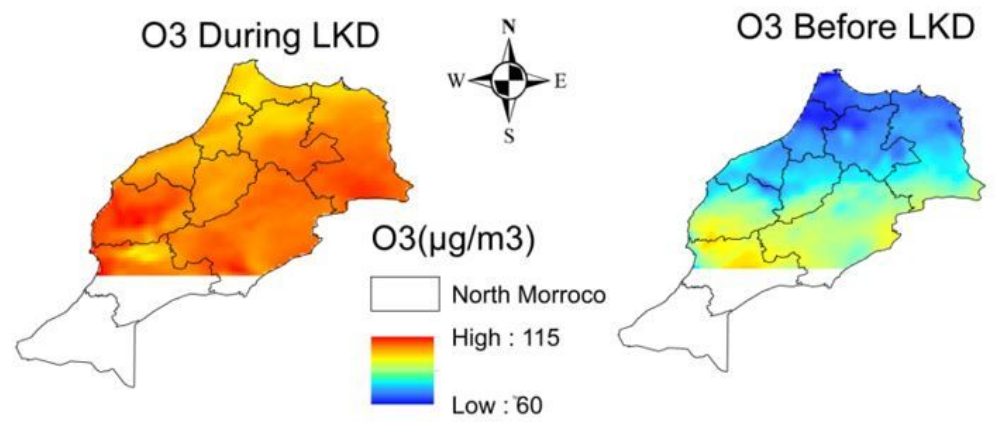

NO2 During LKD
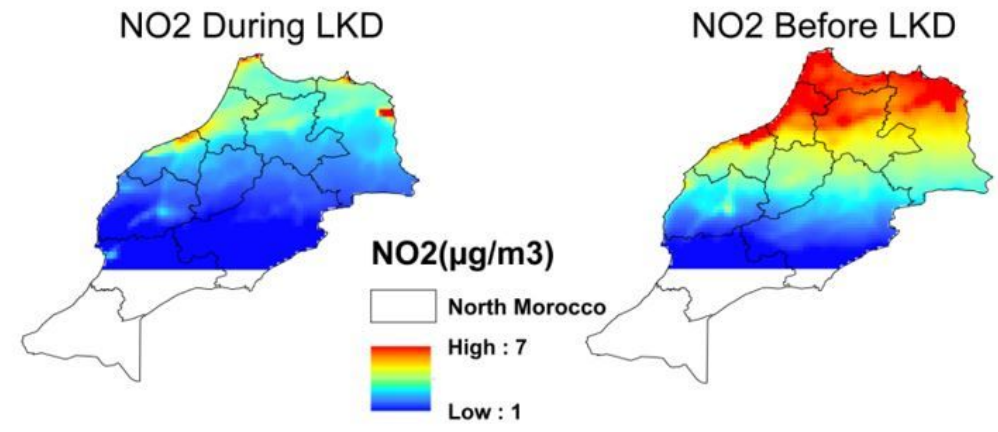

PM2.5 During LKD

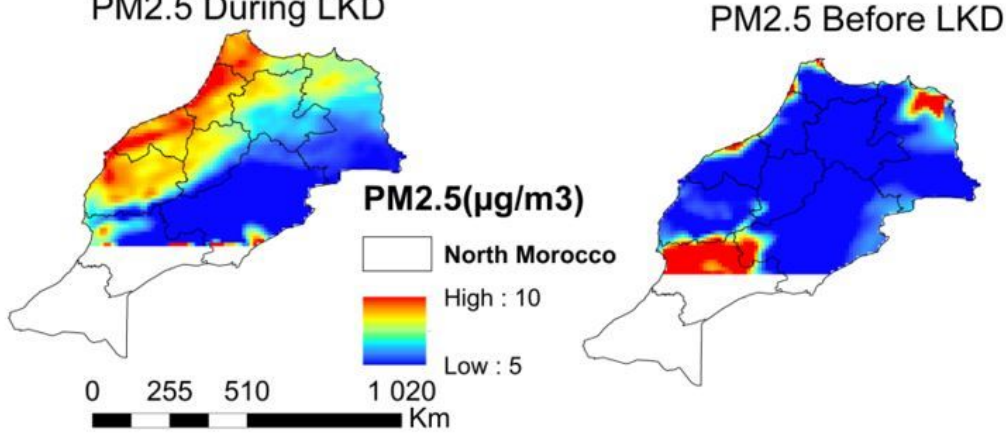

Figure 1

Spatial patterns for 03, NO2 and PM2.5 before and during COVID-19 pandemic lockdown over north of Morocco 

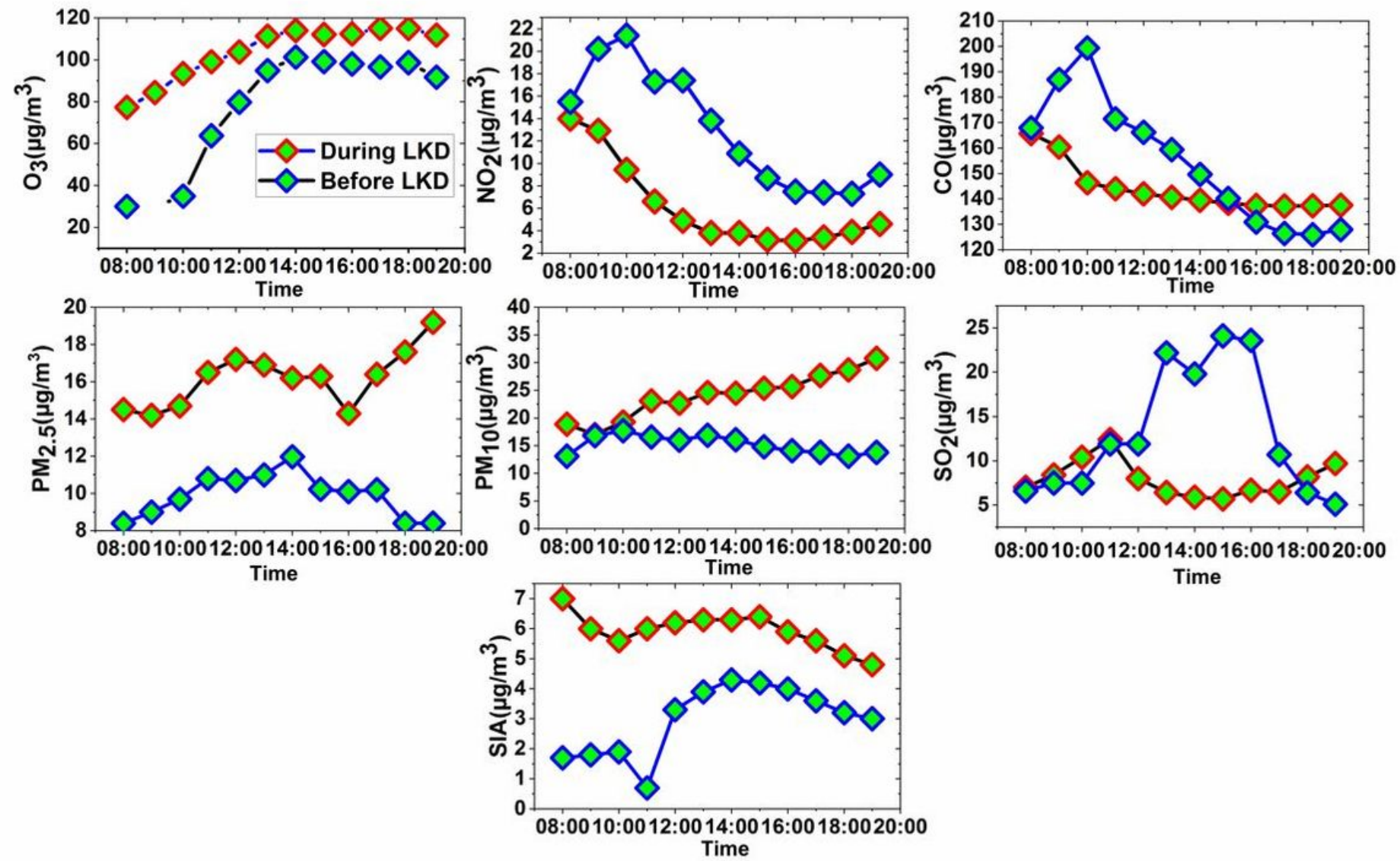

Figure 2

The daily variation of 03 , NO2, CO, PM2.5, PM10, SO2 and SIA before and during LKD in Casablanca 

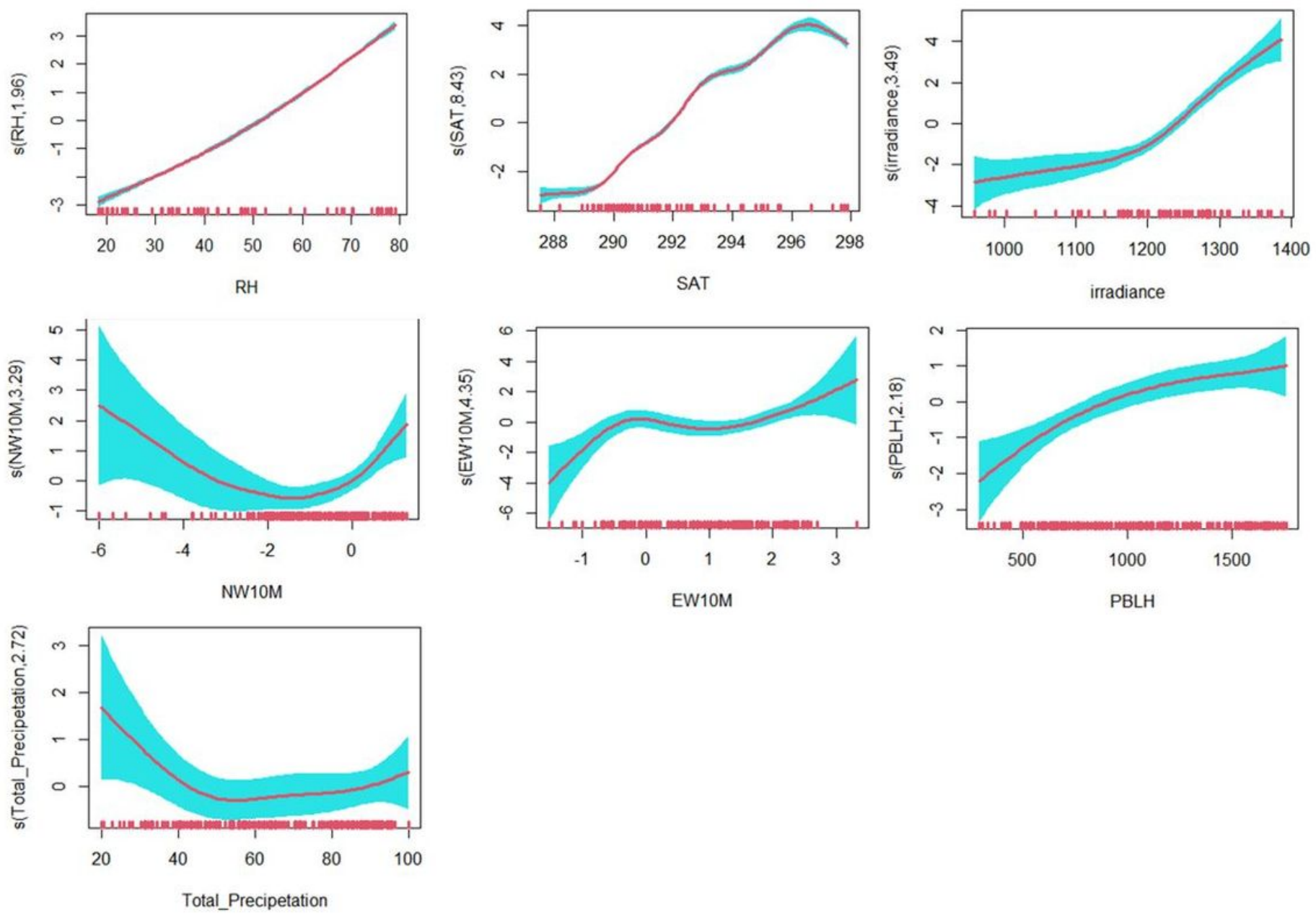

\section{Figure 3}

Marginal effect of individual meteorological variables including: Humidity (RH), Surface air temperature (SAT), wind direction including Eastward wind at 10m (EW10M) Northward Wind at 10m (NW10M), Total Precipitation (TP), Irradiance, Planetary Boundary Layer Height (PBLH) on PM2.5 mass concentration. Shaded bands represents the point wise $95 \%$ confidence interval. The estimated degrees of freedoms (EDFs), which show the linear or nonlinear degree of fitting, corresponding to the individual terms are noted in each figure. An EDFs of 1 indicates a linear effect.
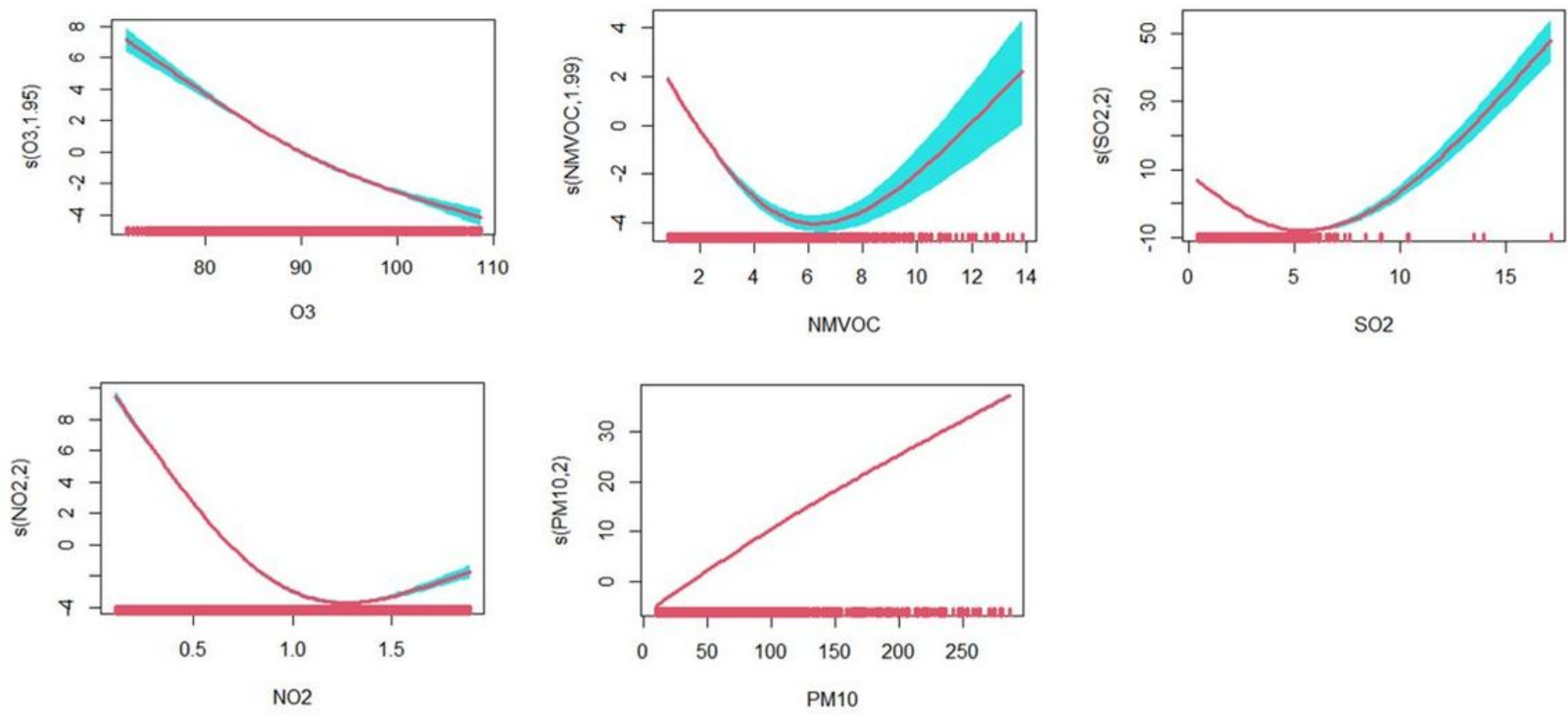

Page $13 / 16$ 
Figure 4

Marginal effect of individual pollutants (NO2, SO2, NMVOC , 03, PM10) on PM2.5 mass concentration during lockdown.
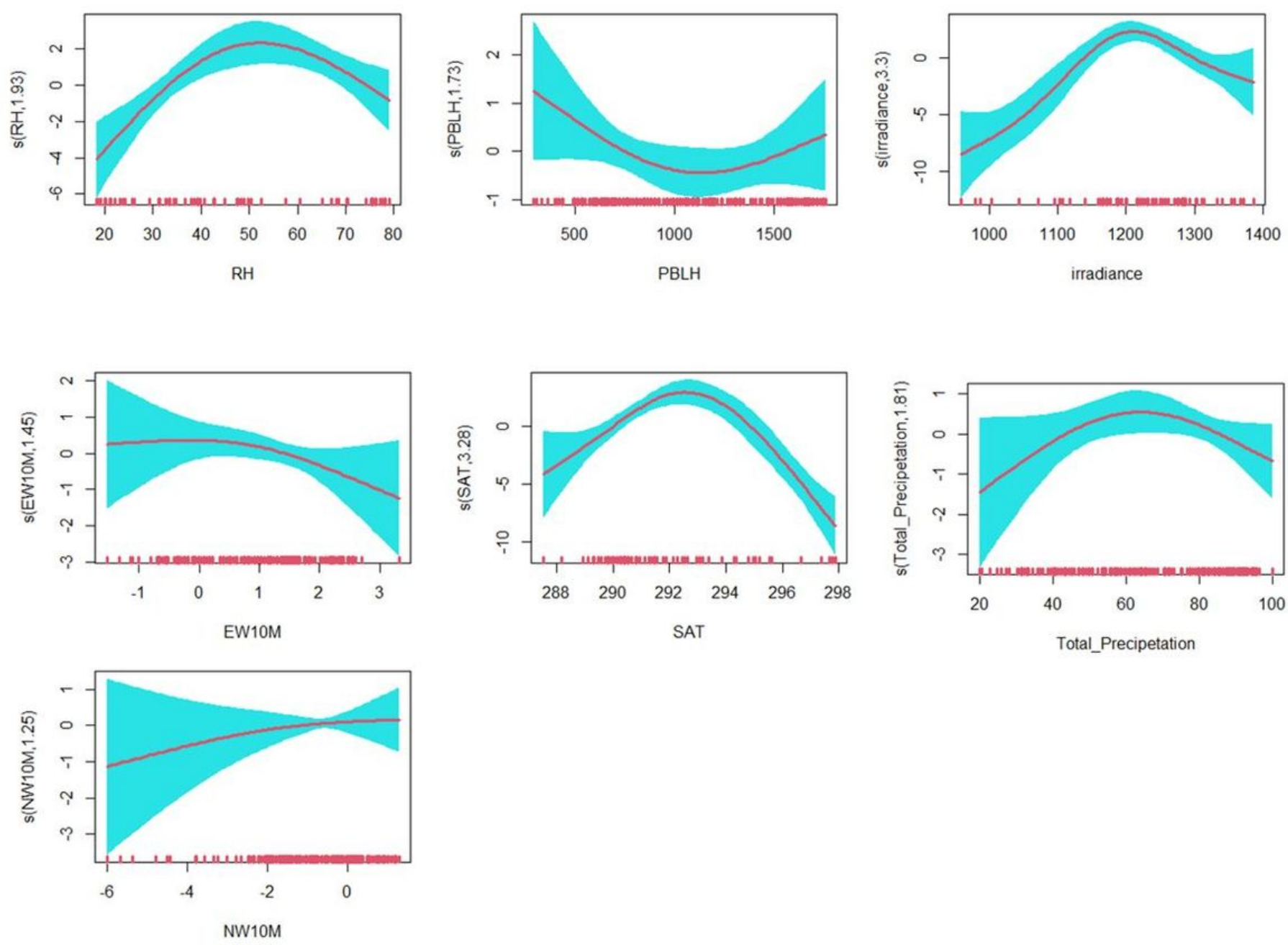

\section{Figure 5}

Similar to figure 3 but for ozone 

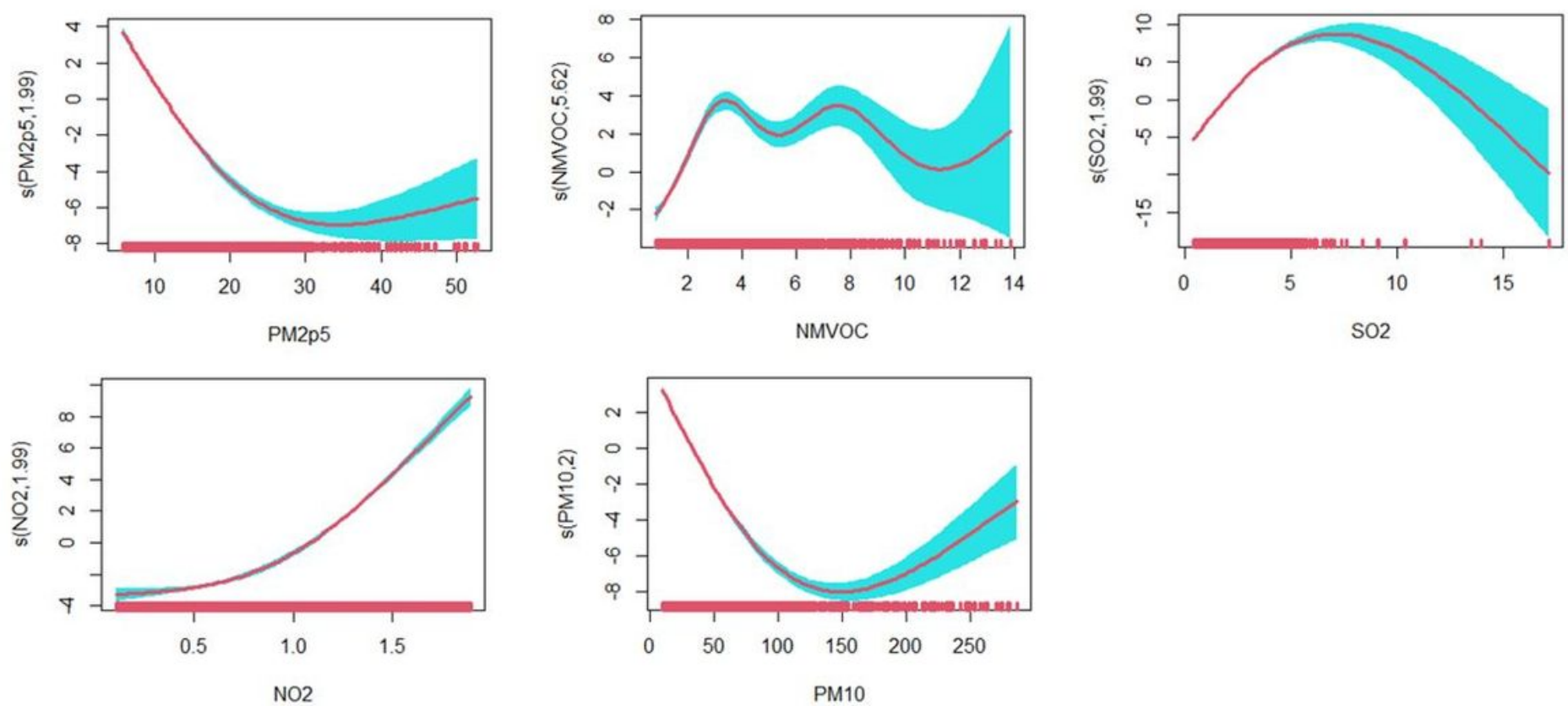

Figure 6

Similar to figure 4 but for ozone.
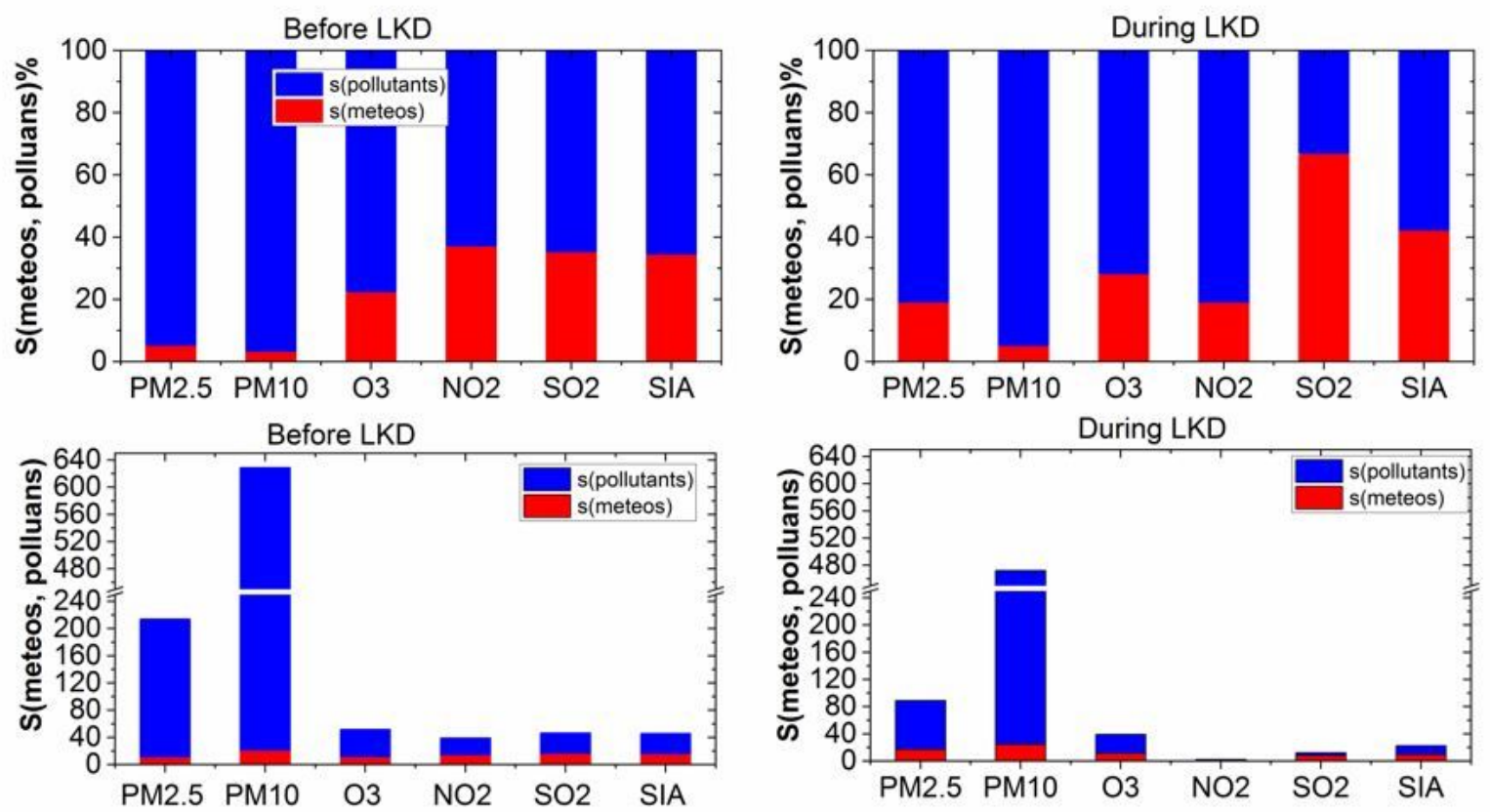

Figure 7

The bar plots of marginal effect of individual pollutants s(pollutants) (bleu) and meteorological parameters s(meteos) (red) and their percentage to contribution in air pollutants mass concentration before and during lockdown period 

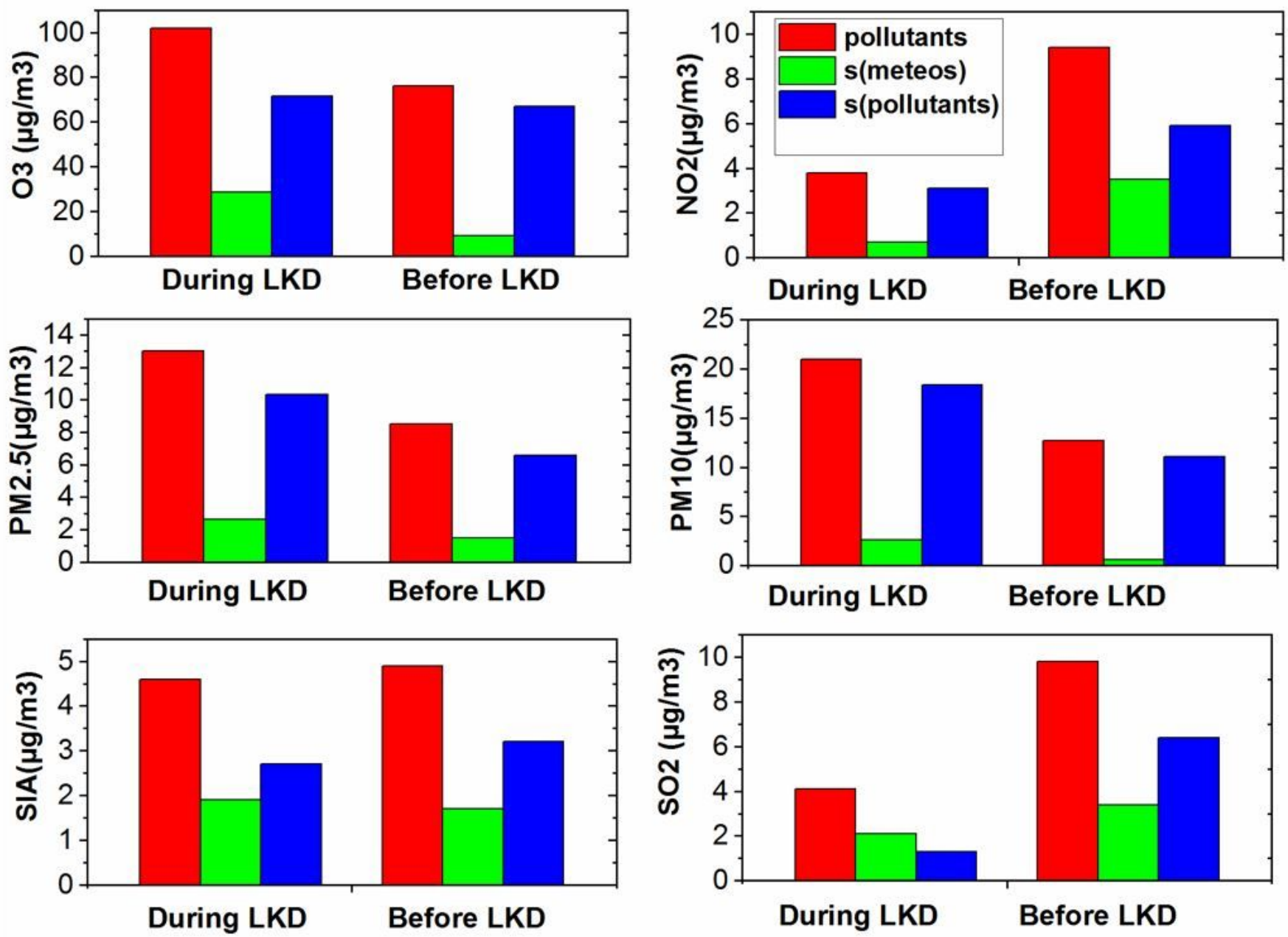

Figure 8

The bar plots of pollutants averages mass concentration in Casablanca downtown and contribution of meteorological parameters $\mathrm{s}(\mathrm{meteos})$ and pollutants $s$ (pollutants)to each pollutant mass concentration during and before lockdown

\section{Supplementary Files}

This is a list of supplementary files associated with this preprint. Click to download.

- SupportinginformationAIRQualityinMorocco.docx 